\title{
ANALYSIS HYSTERESIS CLUTCH TECHNICAL CHARACTERISTICS OF THE SHUT-OFF VALVES ELECTRICAL DRIVE SYSTEM
}

\author{
Maria V. Saveleva ${ }^{1}$, and Nadejda Y. Sipaylova ${ }^{1, *}$ \\ ${ }^{1}$ Tomsk Polytechnic University, 634050, Tomsk, Russia ${ }^{1}$
}

\begin{abstract}
The results of calculations of the hysteresis clutches of various designs for use in electric shut-off valves of the pipeline. The possibility of using the clutch with an axial air gap for a wide range of electric power.
\end{abstract}

\section{Introduction}

The shut-off valves are used to shut off the pipeline sections. In particular, the shut-off valves are installed in the main oil pipelines every $15-20 \mathrm{~km}$. Often, the shut-off valve is equipped with the electric drive, which are essential components of an asynchronous motor and gearbox (worm or wave) [1].

Power shut-off valves should provide gate breakdown from rest and sealing the end of the course, be able to remote control, comply with explosion-proof and climate performance. As often as the shut-off valve is used wedge gate [2], the tightness of the system in the first place depends on the wear of the wedge. To increase its service life it is necessary to force the end of the course provides a reliable contact, but do not over-tighten the wedge.

\section{Formulation of problem}

The problem of reducing the seals of the wedge in the shut-off valve with the passage of time can be solved with the help of:

- Using a frequency converter as a part of electric drive, which will allow to precisely control the force developed by the motor at all stages of valve operation. However, this option is quite expensive for widespread implementation;

- Replacement of the induction motor synchronous hysteresis motors, which control will be performed using a PWM [3], which is also an expensive option;

- The introduction to the electric drive hysteresis clutch.

Hysteresis clutch belongs to a class of synchronous magnetic coupling and is used for non-contact transmission of mechanical torque from the drive shaft to the output. The advantages of the hysteresis coupling, important for the operation as part of the drive of valves are:

\footnotetext{
* Corresponding author: sny@,tpu.ru
} 
- Having its own starting point, which will allow for the failure of the gate from the rest;

- Set the maximum transmitted torque, eliminates pinched wedge at the end of the course;

- The clutch can be introduced into the electric drive, slighty complicating the structure thereof;

- Compliance with the terms of explosion and low sensitivity to temperature changes [4]. The disadvantages which can be isolated from the hysteresis coupling include the use in the manufacture of complex materials hard-magnetic and functioning own characteristics different constructions described below.

The basic design of the hysteresis clutches are shown in Figure 1.

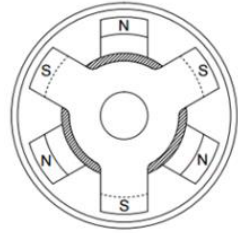

a)

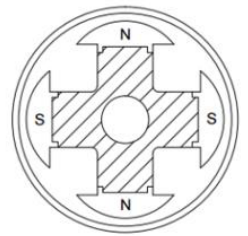

b)

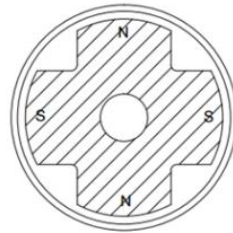

c)

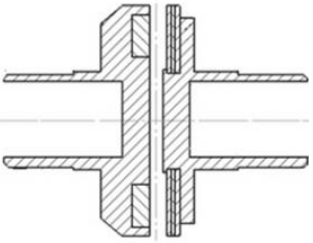

d)

Fig. 1. The hysteresis clutch a) clawlike inductor; b) radially spaced from the magnets and pole piece; c) with the inductor of the "asterisk"; g) butt magnetization.

Clawlike inductor (Figure 1, a) consists of a cylindrical permanent magnet having on the ends of the soft magnetic steel washers with clawlike projections. The main advantage of the inductor is that the permanent magnet is protected from the external elements of the soft magnetic field, and its initial magnetization is performed in the assembled external uniform field. Therefore, the degree of utilization of the magnet is high and labor induction is 0.6-0.7 Tesla. Furthermore, the magnet has a simple shape and is situated near the center of the inductor, which allows to realize the inductor circumferential speed of $80-100 \mathrm{~m} / \mathrm{s}$, because the outer soft magnetic elements have sufficient mechanical strength. Therefore, power of machines with clawlike inductor can reach $10-20 \mathrm{kV} \cdot \mathrm{A}[5]$.

Inductor of hysteresis clutch with radially arranged magnets and pole pieces (Figure 1, b) has an average value of the induction of labor among the presented designs, but has a worse fill factor magnet and a more complex structure compared with the inductor of the "asterisk".

The design of inductor type "asterisk" (figure 1c) comprises a six-pointed molded permanent magnet which is fastened to the shaft by casting a nonmagnetic alloy (based on aluminum or zinc). Inductor Advantages - simplicity and high filling rate of a magnet. Disadvantages include low mechanical strength because of the fragility hard-magnetic alloy and residual stress in the casting. Maximum allowable inductor circumferential speed is 40 $50 \mathrm{~m} / \mathrm{s}$, and the workers do not exceed 0.2-0.4 induce T, thereby asterisk inducer is usually used at a relatively low power machine $(10 \mathrm{kVA})$.

Hysteresis clutch with an axial air gap (Figure 1, d) and the butt is the magnetization inductor with alternating poles clawlike type on the drive shaft. The driven coupling part comprises a hysteresis layer which holds a laminated or cast and enclosed in the armature of soft magnetic or non-magnetic material and may also be carried out without any reinforcement.

Energy losses in the magnetic hysteresis clutches in synchronous transmission mode is small, because they are determined by the friction losses in the bearings, air friction losses and eddy currents in the electrically conductive nonmagnetic wall. Thus the efficiency of the magnetic of hysteresis clutch is extremely high, approaching unity. 
Estimation of optimal design of magnetic hysteresis clutches in terms of the energy characteristics of secondary importance, as the loss of energy in it is small.

In couplings with a radial air gap misalignment due to manufacturing errors technology leads to uneven air gap, which adversely affects the characteristics of the coupling and creates radial forces on the bearings due to violations of magnetic symmetry. The clutches with axial air gap misalignment less impact on non-uniformity of the gap and the coupling characteristics, so manufacturing techniques clutches with radial air gap requires more precision than for the coupling with the axial air gap.

The clutches with radial air gap, it is possible to develop a series of couplings with different hysteresis torque value based on one of the external diameter with the same geometry of the active parts. The clutches with axial air gap, these possibilities are limited, since their optimal axial length is operably linked to the outer diameter.

For large values of the desired hysteresis torque coupling with a radial air gap becomes more rational than the clutch with an axial air gap since the first allows you to get the required amount of hysteresis torque by increasing the axial length, without increasing the outer diameter. With a uniform air gap in the sleeve with radial clearance no radial forces of magnetic attraction and unilateral axial forces. In couplings with axial air gap having an axial magnetic attraction force acting on the bearing, inversely proportional to the magnitude of the air gap [6].

\section{Conducted calculations}

Based on the range of engines used in the composition and on the basis of the electric drive YUNDK35T5AA materials and Fe-Cr-Co sizes were calculated hysteresis clutches required for transmitting a predetermined torque value. Tables 1 and 2 were built on the information received.

Table 1. Dimensional specifications of hysteresis clutch.

\begin{tabular}{|c|c|c|c|c|c|c|c|c|c|c|}
\hline \multicolumn{3}{|c|}{ Motor specifications } & \multicolumn{8}{|c|}{ Clutch Specifications } \\
\hline \multirow[b]{2}{*}{$\mathrm{P}$} & \multirow[b]{2}{*}{$\mathrm{T}$} & \multirow[b]{2}{*}{$D_{\text {in.m. }}$} & \multirow[b]{2}{*}{$D_{\text {out.h. }}$} & \multirow[b]{2}{*}{$\mathrm{V}_{\mathrm{h}}$} & \multicolumn{3}{|c|}{ Radial gap } & \multicolumn{3}{|c|}{ Axial gap } \\
\hline & & & & & $D_{\text {inh }}$ & $\mathrm{L}_{\mathrm{h}}$ & $\lambda$ & $D_{\text {in.h }}$ & $\Delta_{\mathrm{h}}$ & $\Delta_{\mathrm{h}} *$ \\
\hline $\begin{array}{c}\text { powe } \\
\text { r }\end{array}$ & $\begin{array}{c}\text { torqu } \\
\mathrm{e}\end{array}$ & $\begin{array}{c}\text { motor } \\
\text { inner } \\
\text { diamete } \\
r\end{array}$ & $\begin{array}{l}\text { outer } \\
\text { diameter } \\
\text { of the } \\
\text { hysteresis } \\
\text { layer }\end{array}$ & $\begin{array}{c}\text { volume } \\
\text { of } \\
\text { hysteresis } \\
\text { layer }\end{array}$ & $\begin{array}{c}\text { inner } \\
\text { diameter of } \\
\text { the } \\
\text { hysteresis } \\
\text { layer }\end{array}$ & $\begin{array}{l}\text { length } \\
\text { of the } \\
\text { inducto } \\
r\end{array}$ & $\begin{array}{l}\text { constr. } \\
\text { factor }\end{array}$ & & $\begin{array}{l}\text { height } \\
\text { of } \\
\text { hysteres } \\
\text { is layer }\end{array}$ & $\begin{array}{l}\text { relative } \\
\text { height } \\
\text { of } \\
\text { hysteres } \\
\text { is layer }\end{array}$ \\
\hline $\mathrm{kW}$ & $\mathrm{N} \cdot \mathrm{m}$ & $\mathrm{cm}$ & $\mathrm{cm}$ & $\mathrm{cm}^{3}$ & $\mathrm{~cm}$ & $\mathrm{~cm}$ & & $\mathrm{~cm}$ & $\mathrm{~cm}$ & \\
\hline 0.55 & 0.4 & 20 & 18 & 23.26 & 17.5 & 5.46 & 0.27 & 6.30 & 0.109 & 0.01 \\
\hline 1.5 & 1 & 20 & 18 & 58.15 & 17.5 & 13.65 & 0.68 & 6.30 & 0.271 & 0.02 \\
\hline 2.5 & 1.7 & 25 & 22.5 & 98.85 & 22 & 18.51 & 0.74 & 7.88 & 0.295 & 0.01 \\
\hline 4 & 2.7 & 25 & 22.5 & 157.00 & 22 & 29.40 & 1.18 & 7.88 & 0.469 & 0.02 \\
\hline 7.5 & 5 & 35 & 31.5 & 290.74 & 31 & 38.77 & 1.11 & $\begin{array}{c}11.0 \\
3\end{array}$ & 0.443 & 0.01 \\
\hline 11 & 7.3 & 35 & 31.5 & 424.48 & 31 & 56.60 & 1.62 & $\begin{array}{c}11.0 \\
3\end{array}$ & 0.647 & 0.02 \\
\hline 18.5 & 12.3 & 35 & 31.5 & 715.22 & 31 & 95.36 & 2.72 & $\begin{array}{c}11.0 \\
3\end{array}$ & 1.09 & 0.03 \\
\hline 30 & 20 & 40 & 36 & 1162.96 & 35.5 & 135.54 & 3.39 & $\begin{array}{c}12.6 \\
0\end{array}$ & 1.357 & 0.04 \\
\hline 45 & 30 & 45 & 40.5 & 1744.44 & 40 & 180.58 & 4.01 & $\begin{array}{c}14.1 \\
8\end{array}$ & 1.608 & 0.04 \\
\hline
\end{tabular}


Table 2. Torque values of different hysteresis clutches.

\begin{tabular}{|c|c|c|c|c|c|c|c|c|c|c|c|c|c|}
\hline & & & & & & & & $\operatorname{Rad}$ & 1 gap & clutch & & & \\
\hline & Axial g & ap clut & & & & $\begin{array}{l}\text { ar" } \\
\text { dduc }\end{array}$ & & & $\begin{array}{l}\text { le pi } \\
\text { duct }\end{array}$ & & Claw & ike inc & uctor \\
\hline $\mathrm{D}$ & $\lambda$ & $\sigma_{\text {mg.m, }}$ & $\mathrm{M}_{\mathrm{h}}$ & D & $\lambda$ & $\begin{array}{l}\sigma_{\mathrm{m}} \\
\text { g.m. }\end{array}$ & $\mathrm{Mh}$ & $\lambda$ & $\begin{array}{l}\sigma_{\mathrm{m}} \\
\text { g.m. }\end{array}$ & $\mathrm{M}_{\mathrm{h}}$ & $\lambda$ & $\begin{array}{c}\sigma_{\mathrm{mg}} \\
\mathrm{m} .\end{array}$ & $\mathrm{M}_{\mathrm{h}}$ \\
\hline $\begin{array}{c}\text { outer } \\
\text { clutch } \\
\text { diamete } \\
r\end{array}$ & $\begin{array}{l}\text { const } \\
r . \\
\text { facto } \\
r\end{array}$ & $\begin{array}{c}\text { active } \\
\text { mater } \\
\text { ials } \\
\text { using } \\
\text { factor }\end{array}$ & $\begin{array}{l}\text { hyster } \\
\text { esis } \\
\text { torque }\end{array}$ & & & & & & & & & & \\
\hline $\mathrm{cm}$ & & $10^{-3}$ & $\mathrm{~N} \cdot \mathrm{m}$ & $\mathrm{cm}$ & & $10^{-3}$ & $\mathrm{~N} \cdot \mathrm{m}$ & & $10^{-3}$ & $\mathrm{~N} \cdot \mathrm{m}$ & & $10^{-3}$ & $\mathrm{~N} \cdot \mathrm{m}$ \\
\hline 18 & 0.5 & 1.34 & 3.91 & 17.5 & - & 1.5 & & - & 1 & & - & 0.63 & \\
\hline 18 & 0.5 & 1.34 & 3.91 & 17.5 & 0.76 & 1.5 & 6.1 & 0.76 & 1 & 4.1 & 0.76 & 0.63 & 2.56 \\
\hline 22.5 & 0.5 & 1.34 & 7.63 & 22.0 & 0.82 & 1.5 & 13.1 & 0.82 & 1 & 8.7 & 0.82 & 0.63 & 5.51 \\
\hline 22.5 & 0.5 & 1.34 & 7.63 & 22.0 & 1.31 & 1.5 & 20.8 & 1.31 & 1 & 13.9 & - & & \\
\hline 31.5 & 0.5 & 1.34 & 20.9 & 31.0 & 1.23 & 1.5 & 54.9 & 1.23 & 1 & 36.6 & - & & \\
\hline 31.5 & 0.5 & 1.34 & 20.9 & 31.0 & 1.80 & 1.5 & 80.2 & 1.80 & 1 & 53.5 & - & & \\
\hline 31.5 & 0.5 & 1.34 & 20.9 & 31.0 & - & 1.5 & & - & 1 & & - & & \\
\hline 36 & 0.5 & 1.34 & 31.3 & 35.5 & - & 1.5 & & - & 1 & & - & & \\
\hline 40.5 & 0.5 & 1.34 & 44.5 & 40.0 & - & 1.5 & & - & 1 & & - & & \\
\hline
\end{tabular}

\section{Conclusion}

The preliminary assessment of the hysteresis clutch with an axial air gap are more promising for use in the electric drive of shut-off valves, as they meet all the specified requirements to the coupling as a whole, are able to work in all aspects ranging and significantly affect on the drive dimensions, unlike couplings with radial magnetization. In general, due to its simplicity and relatively low cost of the materials used can be to talk about the possible use of the hysteresis clutches and in other industries where currently used asynchronous motors with direct start.

\section{References}

1. G. Sevastyanihin, Science and Construction, 5, (2006)

2. A. Garganeev, A. Karakulov, S. Landgraf, Power shut-off valves: monograph (Publishing House of Tomsk Polytechnic University, Tomsk, 2012) [in Russian]

3. A. Garganeev, D. Padalko, A. Chervatyuk, Reports TUSUR, 2, 32 (2014) [in Russian]

4. Operating Instructions Power torque limiting explosion-proof two-way clutch for valves DN 500-1200b PN 8,0-15,0 (TOMZEL, Tomsk, 2013) [in Russian]

5. V. Booth, Contactless electrical machines (Vysshaya Shkola, Moscow, 1990) [in Russian]

6. S. Mizyurin, M. Ermilov, Design magnetic hysteresis clutches (Publishing House of MAI, Moscow, 1966) [in Russia] 